\title{
Percepção dos auditados sobre as práticas de auditoria interna em uma cooperativa de crédito
}

\section{Cintia Tais Klamt Bussler, Jair Antonio Fagundes, Edio Polacinski, Clébia Ciupak Ferreira y Alex Fabiono Bertollo Santana}

\author{
IESA/CNEC - Brasil \\ SIM Contabilidade e Gestão \\ Universidade Regional Integrada - Brasil \\ Universidade Federal do Mato Grosso- Brasil \\ Universidade do Minho - Portugal
}

Este artigo apresenta a percepçáo dos auditados sobre as práticas de auditoria interna em uma Cooperativa de Crédito. O objetivo deste estudo foi analisar a percepção dos auditados sobre as práticas da auditoria interna em uma cooperativa de crédito e verificar através das percepçóes dos auditados suas características pessoais e os aspectos da auditoria interna entre setores da organização. A metodologia utilizada para o desenvolvimento da pesquisa foi exploratória seguida de um estudo de caso, com uso dos métodos qualitativo e quantitativo. A coleta de dados deu-se por meio de uma entrevista semiestruturada aplicada aos colaboradores da organizaçáo em estudo. De acordo com os resultados da pesquisa, obteve-se diferentes percepçóes de auditoria interna de acordo com cada aspecto analisado, isto também se justifica pelo fato de ser aplicado em diferentes setores da organização. Desta maneira a ampliação do conhecimento sob as práticas da auditoria interna serve de apoio para o planejamento e melhoria nos processos organizacionais assim como of feedback desta pesquisa que foi apresentado para seus gestores.

Palavras-chave: cooperativa de crédito, percepção, auditoria interna, auditado.

\section{Perception of audited on the practice of internal audit on a credit cooperative}

This article presents the perception of audited on internal audit practices in a credit union. The aim of this study was to analyze the perception of audited on the practices of internal audit in a credit union and check through the perceptions of the audited personal characteristics and aspects of internal audit of the organization sectors. The methodology used for the development of the research was exploratory followed by a case study with use of qualitative and quantitative methods. Data collection took place through a semi-structured interview applied to the organization's employees in the study. According to the survey results, was obtained different perceptions of internal audit in accordance with each aspect analyzed, this is also justified by the fact of being applied in different parts of the organization. Thus the expansion of knowledge in the practice of internal audit serves as support for planning and improvement in organizational processes as well as the feedback from this survey that was presented to their managers.

Keywords: Credit Cooperative, Perception, Internal audit, Audited. 


\section{Percepción de las personas auditadas sobre las prácticas de auditoría interna en una cooperativa de crédito}

Este artículo presenta la percepción de los auditados con respecto a las prácticas de auditoría interna en una Cooperativa de crédito. El objetivo de este estudio fue analizar la percepción de las personas auditadas sobre las prácticas de la auditoría interna en una cooperativa de crédito y verificar, a través de las percepciones de los auditados, sus características personales y los aspectos de la auditoría interna en los sectores de la organización. La metodología utilizada fue la investigación exploratoria seguida de un estudio de caso, usando métodos cualitativos y cuantitativos. La recolección de datos se hizo a través de una entrevista semi-estructurada aplicada a los colaboradores de la organización en estudio. De acuerdo con los resultados de la investigación, se obtuvieron diferentes percepciones según cada aspecto analizado, esto también se justifica por el hecho de ser aplicado en diferentes sectores de la organización. De esta manera, se amplía el conocimiento de las prácticas de auditoría interna, lo cual sirve de apoyo para la planificación y mejora de los procesos organizacionales, así como de feedback para esta investigación que fue presentada para los directivos.

Palabras clave: Cooperativa de crédito, Percepción, Auditoría interna, Auditados.

\section{Introdução}

A auditoria interna influencia intensivamente nas organizaçóes assim como nas cooperativas de crédito, onde auxilia cada vez mais para o aperfeiçoamento de seus produtos e serviços, visto que as mesmas estão sempre em constante desenvolvimento e para tanto novas ferramentas são utilizadas para gestão de qualidade de suas atividades.

Desta maneira a auditoria interna é considerada um instrumento de trabalho, que pode ser utilizado para prevenção e correção de falhas, fornecendo assim uma melhora contínua tanto para a instituição financeira como para quem utiliza seus produtos e serviços, ou seja, seus associados, investidores, clientes e demais usuários que de alguma maneira utilizam-se de serviços ou produtos.

Dessa forma, a questão de estudo é qual a percepção dos auditados sobre as práticas da auditoria interna em uma cooperativa de crédito? Assim delineou-se o objetivo, qual seja, analisar a percepção dos auditados sobre as práticas da auditoria interna em uma cooperativa de crédito e verificar através das percepçóes de cada um dos auditados suas características pessoais e também os aspectos da auditoria interna entre os diferentes setores da organização em estudo. Este conjunto de fatores analisados através das entrevistas e dos demais dados coletados tornaram evidente que a auditoria interna contribui para a melhoria da gestão organizacional.

Contextualmente o estudo foi realizado nas unidades de atendimento da cooperativa de crédito no município de Ijuí, Tupanciretã e Jóia todas no estado do Rio Grande do Sul, cuja temática é a percepção dos auditados sobre as práticas de auditoria interna, dando continuidade ao estudo de Lélis e Pinheiro (2012) e também ao estudo de Kogeliski, Teixeira e Fagundes (2014).

Esta pesquisa tem sua relevância pela importância e necessidade de ter conhecimento sobre os métodos e processos da cooperativa, justifica-se analisar a percepção dos auditados sobre as práticas de auditoria interna adotadas nas unidades de atendimento. Através dos resultados das percepçóes dos auditados, as informaçôes coletadas foram fornecidas como forma de feedback aos gestores da empresa estudada, visando a melhoria e desenvolvimento continuo dos processos de forma corretiva e preventiva sobre os itens apontados. 


\section{Referencial teórico}

Neste capítulo apresenta-se o referencial teórico, o qual estabelece a revisão da literatura que sustenta o desenvolvimento desta pesquisa. Foi necessário fazer abordagens de vários autores a fim de atender as temáticas em discussão, para então ter um embasamento teórico capaz de subsidiar o desenvolvimento deste artigo. A seguir serão abordados conhecimentos teóricos sobre pesquisas antecedentes, auditoria interna, cooperativa, cooperativas de crédito.

\subsection{Pesquisas antecedentes}

Neste artigo buscou-se apresentar pesquisas realizadas direta ou indiretamente, sobre o tema abordado, foram pesquisados revistas no Qualis que é um conjunto de procedimentos utilizados pela Capes (Coordenação de Aperfeiçoamento de Pessoal de Nível Superior) sendo que esta avalia e lista por níveis e assuntos, conforme avaliação, as publicações científicas de cursos de pós-graduação, onde a classificação A1 é a mais elevada, A2, B1, B2, B3, B4, B5 e C que é igual à zero. Assim foram retirados onze artigos, destes 7 (sete) são do extrato $\mathrm{B} 3$, 1 (um) B2, 2 (dois) B2 e 1 (um) do extrato A1, pois se entendeu de que o estudo seria válido se o assunto já tivesse despertado interesse em outros pesquisadores.

O primeiro artigo segundo Silva e Inácio (2013) tem em seu objeto de estudo a relação entre auditoria interna e a auditoria externa e o impacto nos honorários dos auditores externos, da análise realizada sob este estudo pode-se concluir que nem sempre os esforços dos auditores externos resultam em redução de seus honorários.

O segundo artigo analisado, de Suzart (2012) explorou a questão de ser ou não ser independente? Um estudo exploratório sobre a independência das instituiçóes superiores de auditoria e o nível de transparência fiscal dos países, a partir de vários fatores analisados, percebe-se que o presente artigo atingiu satisfatoriamente seu objetivo identificando a possível relação entre o nível de transparência de um país e o nível de independência de uma ISA. Foi interpretado também que, além do nível de transparência fiscal, outras variáveis interferem no nível de independência.

$\mathrm{Na}$ linha de pensamento das autoras Lélis e Pinheiro (2012) buscou-se avaliar a percepção de auditores e auditados sobre as práticas de auditoria interna de uma empresa brasileira do setor energético, assim os resultados do estudo contribuíram para aumentar o conhecimento sobre auditoria interna, sendo constatada também a importância da preparação do auditor. A percepção apresentada foi positiva sobre as contribuições da auditoria interna para a melhoria dos processos, também a qualidade das recomendaçôes de auditoria.

No estudo de Fajardo e Wanderley (2010) foi elaborado um estudo com a temática planejamento estratégico e auditoria de gestão: similaridades com o modelo COSO, sobre este trabalho de avaliação da gestão e de auditoria, conclui-se que existem similaridades entre os modelos de COSO e os trabalhos relacionados com a AVG (Auditoria de Avaliação de Gestão), outro fator de importância destacado no decorrer deste trabalho é sobre a auditoria de processo pois ela trata-se de uma ferramenta de suporte a melhoria contínua.

No artigo de Santos (2008) percebe-se que o autor tem como objetivo de estudo verificar a influência da aplicação dos mecanismos e instrumentos de auditoria nos resultados da Cooperativa de Crédito de uma Instituição Federal de Ensino Tecnológico - CEFET-PB, e a partir deste trabalho, portanto, pode-se dizer que a auditoria hoje é o recurso cada vez mais utilizado pelos gestores, estes que estáo conscientes dos benefícios e vantagens que a auditoria proporciona em uma organização, neste caso em uma cooperativa de crédito. 
Ressaltando ainda que auxilia no sucesso do alcance dos resultados organizacionais.

Soares (2007) realizou um estudo onde o objetivo do artigo foi demonstrar de que maneira a auditoria interna pode colaborar com uma instituição hospitalar, com o propósito de diminuir riscos para manutenção do certificado de filantropia, e de propor, para os gestores, sugestóes de melhoria nos processos. Neste trabalho também se verificou uma serie de conceitos sobre auditoria interna e controles internos. Soares (2007) demonstrou em seu artigo de que maneira a auditoria interna pode colaborar com uma instituiçáo hospitalar, assim também buscou demonstrar como minimizar riscos para manutenção do certificado de filantropia. A partir de teorias e práticas sobre auditoria interna foi possível transparecer os benefícios que a mesma proporciona nas atividades hospitalares filantrópicas.

O trabalho dos autores Borely e Cardoso (2005) objetivou examinar a auditoria como ferramenta estratégica de controles de ONGs, estimando que este setor na economia está alavancando, assim, as ONG sáo tratadas como o terceiro setor. Dessa forma, no momento de distribuição de recursos a tomada de decisão se torna mais coerente, concluem abordando que a auditoria é uma ferramenta estratégica, rica fonte de informaçóes, onde os dados estáo interligados ajudando de forma geral para o mundo.

No estudo de Kogeliski, Teixeira e Fagundes (2014), as autoras realizaram análise sob as percepçóes dos auditados sobre as práticas de auditoria interna, onde foi possível analisar e realizar comparaçóes entre os aspectos de auditoria interna em uma unidade de atendimento de uma cooperativa de crédito sendo que se obtiveram diferentes percepçóes de acordo com cada item analisado onde foram apresentados aos gestores o feedback desta pesquisa.
O último artigo analisado foi de Silva (2002), o objetivo deste estudo foi o controle enquanto função da Ciência da Administração e sua utilização como principal objeto da Auditoria Interna, em especial controlar a evolução dos controles internos na administração pública, os fatores analisados foram às competências, o comprometimento, estabelecendo um grande elo entre os gestores e demais entidades relacionadas ao tema abordado como um todo.

Importante ressaltar, que não basta apenas existir um setor de auditoria na organização, pois, se deve fazer um diagnóstico da possível cumplicidade dos controles internos, ou seja, verificar se os mesmos estáo atingindo seus objetivos, trazendo confiabilidade aos relatórios contábeis, financeiros, buscando a eficiência operacional e preservando os interesses da organização.

\subsection{Auditoria interna}

A evolução da auditoria foi consequência do desenvolvimento da contabilidade. A partir do surgimento das empresas de capital aberto e de organizaçóes multinacionais, com a maior complexidade na administração dos negócios e com o crescimento da economia, tornou-se necessário realizar as auditorias externas para verificar os controles internos e examinar a exatidão das demonstraçóes contábeis e balanços elaborados em um determinado período.

No decorrer do tempo, percebeu-se a necessidade de formar esquipes de funcionários que fossem permanentes para realizar o acompanhamento das rotinas operacionais, observar e analisar o devido cumprimento das normas e regulamentos das diretrizes e também reduzir os gastos com auditoria externa; assim surgiu então a figura do auditor interno. Para Franco (2001, p. 218) a auditoria interna «é aquela exercida por funcionários da própria empresa, em caráter permanente», e, tem proporcionado segurança para os empresários 
que procuram maior clareza em relação ao patrimônio da organização e assessorado os administradores na tomada de decisão (Oliveira, Gomes e Porto, 2012).

O processo da auditoria interna está voltado para o controle interno das organizaçóes, é uma ferramenta que auxilia o desempenho das atividades, garantindo assim o desenvolvimento harmônico, adequado e seguro nas açóes, desta maneira também permite um resultado positivo para os diferentes setores da uma empresa e para seus colaboradores. No entendimento de Mello (2002), a auditoria interna é uma atividade de avaliação independente e de assessoramento da administração, tendo como funções da auditoria interna em uma organizaçáo fazer com que todo o conjunto organizacional desempenhe suas atividades com embasamento no que diz os manuais, proporcionando uma maior rentabilidade e aproveitamento do tempo de trabalho. Portanto, pode-se dizer que o exame realizado pelo auditor interno está voltado principalmente para análise dos controles internos, com o objetivo de identificar se as políticas da administração são devidamente obedecidas e se os relatórios que chegam até eles são exatos e completos, com as informaçóes necessárias para fundamentar as decisões da direção da empresa.

\subsection{Cooperativa}

Cooperativa é uma associação autônoma de pessoas que se unem, voluntariamente, para satisfazer aspiraçóes e necessidades econômicas, sociais e culturais comuns, por meio de uma empresa de propriedade coletiva e democraticamente gerida (Crehnor, 2016). A sociedade cooperativa se baseia nos valores da identidade de propósitos e interesses das pessoas que a compõe, ajuda mútua, ação em conjunto, busca de um resultado útil e comum a todos, responsabilidade, igualdade, solidariedade, democracia e participaçáo (Ancosol, 2016; Crehnor, 2016).
Segundo Schardong (2003), o cooperativismo é caracterizado como um sistema sócio econômico que se baseia na união das pessoas e através da soma de esforços de cada indivíduo, onde busca melhorar as condiçôes tanto sociais e econômicas dos produtores e também de seus consumidores. O cooperativismo é desenvolvido a partir de associaçóes, estas que são formadas por pessoas, formando assim a cooperativa, onde valorizam o homem e integram à comunidade, portanto, cabe salientar que estas cooperativas não são somente para gera lucro.

No entendimento de Lago e Silva (2011) o cooperativismo está baseado na ajuda mútua, ou seja, tem como princípio básico a cooperação. Buscando assim maior produtividade e rentabilidade para as famílias associadas, portanto, os indivíduos unem-se para atuar em mercados concorrenciais mais sofisticados. Ainda para os autores o cooperativismo refere-se como um detentor de características particulares no que tange à constituição e gestão de determinada cooperativa, mas muito sujeito às mesmas pressões do mercado do ponto de vista de desafios e novas oportunidades.

\subsection{Cooperativas de crédito}

As cooperativas estão divididas conforme suas atividades, denominadas de «ramos», desta forma constituem um vasto diferencial como as cooperativas de trabalho, agropecuárias, consumo, infra-estrutura, habitacionais, produção, mistas, ensino e a cooperativa de crédito que nos interessa para o desenvolvimento deste trabalho (Gawlak e Ratzki Apud Wisnievski, 2004).

Quanto às cooperativas de crédito estas devem obrigatoriamente adotar em sua denominação social, a expressão «Cooperativa», onde é vedada à utilização da palavra «Banco». No entanto as cooperativas de crédito têm como órgão fiscalizador e normatizador o Banco Central, este que faz parte do Sistema Financeiro Nacional (SFN), que estão vinculadas as normas e leis que 
as regem. Segundo Macedo e Ximenes (2003, p. 183) as cooperativas de crédito se classificam em: Singulares, sendo construídas por no mínimo 20 (vinte) pessoas físicas; Cooperativas Centrais ou Federaçóes de Cooperativas, sendo, aquelas constituídas pelo numero mínimo de 3 (três) singulares de crédito; e Confederaçóes de Cooperativas, sendo aquelas constituídas, pelo menos, de 3 (três) federaçóes de cooperativas de crédito ou cooperativas centrais de crédito.

\section{Aspectos metodológicos}

O objetivo da metodologia é descrever o tipo de pesquisa realizada, ou seja, identificar quais métodos foram utilizados para o desenvolvimento do trabalho. Quanto aos fins, este estudo pode ser considerado como uma pesquisa descritiva, pois nele são mencionadas as diferentes percepçóes de auditados sobre as práticas de auditoria interna em uma cooperativa de crédito e avaliar as mesmas numa percepção geral entre os setores da organização em estudo.

No entendimento de Vergara (2009, p. 89) quanto aos meios, «a pesquisa de campo é uma investigação empírica realizada no local onde ocorreu um fenômeno ou que dispóe de elementos para explicá-lo». No caso da Cooperativa de Crédito foram realizadas através de entrevistas com os colaboradores da empresa entre seus diferentes setores, sendo utilizado um roteiro de questóes semiestruturadas. Também foram coletados dados a partir de conversas informais com os mesmos, abordando os assuntos de interesse para desenvolvimento desta pesquisa, as quais contribuíram com informações de maneira significativa.

Para Vergara (2009), «o estudo de caso tem caráter de profundidade e detalhamento". Assim o estudo realizado na Cooperativa de Crédito, pode ser visto por diferentes aspectos, pois os dados foram coletados a fim de retratar a realidade da empresa em estudo. Contudo no estudo de caso o universo amostral da problemática, conforme Gil (2002, p. 54), através de um «estudo profundo e exaustivo de um ou de poucos objetos, de maneira que permita seu amplo e detalhado conhecimento». Portanto para o desenvolvimento deste trabalho foram direcionadas quatorze entrevistas para os colaboradores da Cooperativa de Crédito Rural Horizontes Novos de Ijuí, distribuídos entre seus PACS de Ijuí, Jóia e Tupanciretá. Os dados foram coletados entre o período de quinze de fevereiro de 2016 a dezenove de fevereiro de 2016. Foi aplicada uma entrevista semiestruturada para todos os entrevistados entre eles divididos sob a área administrativa da cooperativa, área de negócios, área de atendimento e caixa, onde foram estudadas as características dos colaboradores e em seguida as percepçóes dos auditados quanto as práticas de auditoria interna.

Neste estudo utilizou-se a pesquisa exploratória através da entrevista para coleta de dados, sendo que a mesma seguiu dando continuidade ao estudo de Lélis e Pinheiro (2012, p. 219), e também ao estudo de Kogeliski, Teixeira e Fagundes (2014), assim foi realizado um estudo similar a estas temáticas, através desta pesquisa foi possível responder os objetivos específicos. $\mathrm{O}$ instrumento de pesquisa, portanto, foi dividido em duas partes. A primeira buscou a relaçáo das características pessoais dos entrevistados. A segunda parte buscou a percepção do auditado sobre as práticas de auditoria interna na cooperativa de crédito, onde a partir das respostas coletadas pode-se realizar as analises planejadas para esta pesquisa.

A escolha desta empresa se deu pelo fato dela realizar já há alguns anos auditorias internas, levando-se em consideração a importância desta ferramenta para a transparência da organizaçáo e pela pesquisadora fazer parte do quadro de funcionários desta cooperativa.

Levando em consideração, que é imprescindível identificar as atividades desenvolvidas pela auditoria interna 
da cooperativa, foi necessário a técnica de coleta de dados por intermédio de entrevista estruturada, no qual «desenvolve-se a partir de uma relaçáo fixa de perguntas.» Por sequência, utilizou-se a técnica de observação participante que "consiste na participação real do pesquisador com a comunidade ou grupo.» (Marconi e Lakatos, 2008, p. 79). Quanto aos dados coletados todos os apontamentos realizados pelos sujeitos da pesquisa, e a partir das demais informaçóes coletadas, as quais contribuíram para a elaboração da análise.

Após coletadas todas as informaçóes necessárias para o desenvolvimento desde artigo procedeu-se a interpretação e análise a fim de conseguir resposta ao tema abordado. A análise tem como objetivo organizar e sumariar os dados de tal forma que possibilitem o fortalecimento de respostas ao problema proposto para investigação. Já a interpretação tem como objetivo a procura do sentido mais amplo das respostas, o que é feito mediante sua ligação a outros conhecimentos anteriores obtidos (Gil, 2002, p.168).
Portanto os dados foram organizados e sistematizados de acordo com o tema escolhido e com os objetivos do estudo, de forma qualitativa e quantitativa, por meio do uso de métodos estatísticos, os quais foram interpretados e com base em fundamentações teóricas.

\section{Discussáo dos resultados}

A apresentação e análise dos resultados da pesquisa realizada através de entrevista tiveram por objetivo conhecer as percepções de todos os auditados sobre as práticas de auditoria interna em uma Cooperativa de Crédito. Assim o estudo foi realizado sob a área administrativa da cooperativa, a área de negócio, a área de atendimento no caixa e também no setor da habitação, portanto, cada colaborador respondeu o questionário conforme a realidade do seu setor. A partir disso, no quadro 1, são apresentadas as informaçóes das características gerais de cada um dos quatorze entrevistados, onde neste momento os dados são apresentados de forma individual.

Quadiro 1. Resumo das características gerais dos entrevistados.

\begin{tabular}{|c|c|c|c|c|c|c|}
\hline $\begin{array}{c}\text { Tempoutilizado } \\
\text { para responder }\end{array}$ & Funçáo & $\begin{array}{c}\text { Tempo na } \\
\text { Funçáo }\end{array}$ & $\begin{array}{c}\text { Tempo de } \\
\text { cooperativa }\end{array}$ & $\begin{array}{c}\text { Idade } \\
(\mathbf{a n o s})\end{array}$ & Escolaridade & Género \\
\hline 4 Min. & Gerente Mm. & 9 Anos & 9 Anos & 34 & Sup. Incompleto & Masculino \\
\hline 20 Min. & Setor Habitação & 4 Anos & 4 Anos & 36 & Ens. Méd. Completo & Masculino \\
\hline 10 Min. & Caixa & 6 Meses & 1 Ano & 22 & Sup. Incompleto & Feminino \\
\hline 3 Min. & Caixa & 5 Anos & 5 Anos & 31 & Tec. em Secretariado & Feminino \\
\hline 5 Min. & Conselho Administ. & 3 Anos & 4 Anos & 37 & Ens. Méd. Completo & Masculino \\
\hline 30 Min. & Diretor Pres. & 13 Anos & 13 Anos & 46 & Ens. Méd. Incompleto & Masculino \\
\hline 3 Min. & Aten. Agência & 3 Anos & 6 Anos & 30 & Sup. Completo & Feminino \\
\hline 8 Min. & Aten. Com. Crédito & 1 Ano 5 Meses & 1 Ano 5 Meses & 29 & Pós Graduado & Feminino \\
\hline 5 Min. & Aten. Com. Crédito & 1 Ano 8 Meses & 1 Ano 8 Meses & 33 & Sup. Completo & Masculino \\
\hline 5 Min. & Caixa & 6 Anos & 6 Anos & 27 & Pós Graduado & Feminino \\
\hline 4 Min. & Caixa & 7 Anos & 7 Anos & 33 & Ens. Méd. Completo & Feminino \\
\hline 3 Min. & Aten. Agência & 3 Anos & 3 Anos & 23 & Sup. Incompleto & Masculino \\
\hline 4 Min. & Aten. Agência & 7 Anos & 7 Anos & 32 & Sup. Completo & Feminino \\
\hline 4 Min. & Aten. Agência & 2 Anos & 2 Anos & 34 & Sup. Completo & Masculino \\
\hline
\end{tabular}

Fonte: Dados da pesquisa. 
De acordo com os dados coletados através da entrevista pode-se perceber conforme o quadro 1, que em relação à função dos auditados respondentes desta pesquisa, são dois colaboradores que compóem a área administrativa desta cooperativa estudada, que são o gerente administrativo e o diretor presidente. Verificou-se que na área de negócio, foram cinco colaboradores entrevistados sendo que esta área é composta pelas funçôes de atendente de agência e por agente comunitário de crédito. Já nas funçôes de Caixa que se vincula uma das partes financeiras da cooperativa foram quarto colaboradores entrevistados. Também foram entrevistados três colaboradores que fazem parte dos cargos de engenharia e analista de documentos estes pertencem ao setor da habitação.

De acordo com as informaçóes obtidas apurou-se que apenas um entrevistado possui ensino médio incompleto, já três entrevistados possuem ensino médio completo, também três entrevistados possuem superior incompleto, quatro entrevistados possuem superior completo, dois colaboradores são pós-graduados e por fim uma auditada que possui técnico em secretariado. Neste item identificou-se uma característica que chamou bastante atenção, onde as funçôes que são ocupadas pelos cargos da área administrativa possuem um grau de escolaridade de ensino médio incompleto e superior incompleto.

$\mathrm{Na}$ questáo de gênero dos entrevistados o resultado permite observar que sete deles são do sexo feminino e exatamente a mesma quantidade são do sexo feminino. Assim, percebe-se a importância do trabalho feminino nas organizaçóes. Com o passar do tempo as mulheres passaram a ocupar diversas áreas nas organizaçôes, apresentando crescimento contínuo.

Referente à idade dos entrevistados, apurou-se que cinco colaboradores possuem idade entre 22 a 30 anos; que oito possuem idade entre 31 a 38 anos e apenas um entrevistado tem a idade de 40 anos. A partir desses dados percebe-se que o menor número por faixa etária de entrevistados possui mais de 40 anos, e quem predomina é a faixa etária entre 31 a 38 anos.

Em relação à estimativa de quanto tempo os entrevistados já fazem parte do quadro de colaboradores desta Cooperativa de Crédito, pode-se visualizar que oito dos entrevistados possuem entre 1 a 5 anos, cinco destes possuem de 6 a 10 anos e uma pessoa que possui a função de diretor/presidente com 13 anos de cooperativa. Significa dizer que os colaboradores são também os bens preciosos de uma empresa, onde este fator é importante para se obter resultados positivos com eficácia e eficiência. Outro fator estudado foi o tempo de cada colaborador em sua função, sendo que a maioria deles tem conhecimento nas demais áreas, mas que entrou na empresa para determinada função e permanece até os dias atuais na mesma área.

No decorrer desta pesquisa todos os auditados de maneira generosa se dispuseram a responder a entrevista, com análises da mesma buscou-se seguir a ordem dos aspectos citados. Diante de aspectos similares de alguns, as análises foram agrupadas, onde a percepção negativa tinha o significado de que os auditados percebiam nunca ou quase nunca a ocorrência, a percepção de atenção para quando a mesma acontecia raramente ou às vezes e a percepção positiva para quando ocorria com frequência ou quase sempre.

$\mathrm{Na}$ sequência é apresentado o quadro 2, sendo que o mesmo apresenta uma comparação dos resultados gerais das percepçóes sobre os aspectos da auditoria interna dos estudos já mencionados anteriormente, que são o artigo das autoras Lélis e Pinheiro, também o artigo de Kogeliski, Teixeira e Fagundes e por fim o trabalho da autora desta presente pesquisa, assim verificamos que independente do número de entrevitados existe uma semelhança na maioria dos aspectos questionados e analisados.

Contabilidad y Negocios (12) 23, 2017 / ISSN 1992-1896 
Quadro 2. Comparaçáo dos resultados gerais das percepçóes de auditados sobre os aspectos de auditoria interna dos estudos de Lélis e Pinheiro ao estudo de Kogeliski, Teixeira e Fagundes e também os resultados da presente pesquisa.

\begin{tabular}{|c|c|c|c|c|c|c|c|c|c|c|}
\hline & \multirow{3}{*}{ Aspectos } & \multirow{2}{*}{\multicolumn{3}{|c|}{$\begin{array}{c}\text { Lélis e Pinheiro } \\
(2012)\end{array}$}} & \multirow{2}{*}{\multicolumn{3}{|c|}{$\begin{array}{c}\text { Kogeliski, Teixeira } \\
\text { e Fagundes (2014) } \\
\%\end{array}$}} & \multirow{2}{*}{\multicolumn{3}{|c|}{$\begin{array}{c}\text { Presente } \\
\text { Pesquisa } \\
\%\end{array}$}} \\
\hline & & & & & & & & & & \\
\hline & & Neg. & Aten. & Pos. & Neg. & Aten. & Pos. & Neg. & Aten. & Pos \\
\hline 1. & Aceitaçáo pelo auditado das deficiências encontradas pelo auditor. & 6 & 6 & 88 & 9 & 47 & 44 & 0 & 21 & 79 \\
\hline 2. & Adequação da condução dos trabalhos pelo auditor. & 3 & 11 & 86 & 0 & 24 & 76 & 0 & 14 & 86 \\
\hline 3. & Análise das causas das deficiências pelo auditado & 0 & 7 & 93 & 0 & 47 & 53 & 0 & 14 & 86 \\
\hline 4. & Auditoria como fonte consultiva & 20 & 23 & 57 & 9 & 18 & 73 & 0 & 21 & 79 \\
\hline 6. & Avaliação geral da eficácia do processo de auditoria. & 1 & 20 & 79 & 3 & 41 & 56 & 7 & 7 & 86 \\
\hline 6. & Formalizaçáo e antecedência do aviso de auditoria. & 18 & 4 & 78 & 44 & 21 & 35 & 7 & 7 & 86 \\
\hline 7. & Clima durante a auditoria. & 1 & 9 & 90 & 29 & 53 & 18 & 7 & 64 & 29 \\
\hline 8. & Empenho da área auditada em implementar os planos de ação. & 3 & 14 & 83 & 0 & 24 & 76 & 0 & 14 & 86 \\
\hline 9. & Melhoria dos controles internos. & 2 & 16 & 78 & 3 & 18 & 79 & 14 & 14 & 72 \\
\hline 10. & Melhoria da gestão de riscos. & 5 & 18 & 77 & 3 & 9 & 88 & 0 & 36 & 64 \\
\hline 11. & Melhoria do desempenho dos processos. & 10 & 15 & 75 & 0 & 26 & 74 & 0 & 14 & 86 \\
\hline 12. & $\begin{array}{l}\text { Monitoramento pela auditona da execuçáo dos planos de ação } \\
\text { pelo auditado }\end{array}$ & 3 & 16 & 81 & 9 & 53 & 38 & 0 & 21 & 79 \\
\hline 13. & Preparação do auditor. & 1 & 11 & 88 & 6 & 35 & 59 & 7 & 29 & 64 \\
\hline 14. & Qualidade das recomendaçóes de auditoria. & 2 & 22 & 76 & 0 & 38 & 62 & 0 & 21 & 79 \\
\hline 15. & $\begin{array}{l}\text { Recomendaçóes de auditoria e melhor alinhamento do processo à } \\
\text { estratégia corporativa. }\end{array}$ & 2 & 18 & 80 & 3 & 38 & 59 & 0 & 1 & 93 \\
\hline 16. & Relevância dos resultados reportados. & 1 & 5 & 94 & 0 & 35 & 65 & 0 & 21 & 79 \\
\hline 17. & Tempestividade da comunicaçấo informal. & 13 & 45 & 42 & 6 & 50 & 44 & 0 & 50 & 50 \\
\hline 18. & Tempestividade do relatório de auditoria & 6 & 18 & 76 & 0 & 65 & 35 & 7 & 29 & 64 \\
\hline
\end{tabular}

Fonte: Dados da pesquisa.

Quanto à aceitação pelo auditado das deficiências encontradas pelo auditor (aspecto 1), onde obteve como resultado no presente estudo $79 \%$ positivo e no estudo de Lélis e Pinheiro um indice de $88 \%$ positivo, sendo que aceitam de forma positiva as deficiências encontradas, já no estudo de Kogeliski, Teixeira e Fagundes um percentual de $47 \%$ de atenção e $44 \%$ positivo, assim percebe-se que neste estudo possui uma divergência maior nos resultados das deficiências encontradas.

Nas adequações da condução dos trabalhos pelo auditor (aspecto 2), nos três trabalhos em estudo foram mencionados como respostas os indíces positivos, isto significa que os auditores estáo se especializando cada vez mais buscando aprimorar seus conhecimetos sobre a cooperativa auditada. 
No (aspecto 3) que é a análise das causas das deficiências pelos auditados nenhum dos entrevistados respondeu de forma negativa, portanto demonstra que existe uma reflexão a partir das deficiências encontradas e que estáo distribuídas em sua grande maioria em positividade nos três trabalhos, lembrando que se obteve um pequeno indíce que respondeu ter atenção sob este aspecto analisado.

Sobre o (aspecto 4) que trata da auditoria como fonte consultiva os indíces permanecem em sua grande maioria como positivos, porém nos três trabalhos as respostas estão bem distribuídas, ou seja, no trabalho de Lélis e Pinheiro 57\% respondeu positivo, 23\% respondeu atenção e $20 \%$ negativo. No trabalho de Kogeliski, Teixeira e Fagundes 73\% respondeu positivo, $18 \%$ atenção e $9 \%$ respondeu negativo. Nesta presente pesquisa as respostas ficaram divididas entre $79 \%$ positivo e $21 \%$ atenção. A partir destes resultados fica evidente que conforme o seu local de trabalho e sobre as atividades que os auditados precisam desenpenhar as respostas também foram diferentes, onde alguns entendem que a auditoria é fonte consultiva mas ainda precisa ser melhor trabalhado neste aspecto abordado.

No (aspecto 5) se faz uma avaliação geral da eficácia do processo de auditoria interna, sendo que em ambas as entrevistas o resultado maior foi positivo, onde no presente trabalho se obteve $86 \%$, para Lélis e Pinheiro 79\% e no de Kogeliski, Teixeira e Fagundes 56\%, porém esses dados ainda podem ser melhorados.

Sobre a formalização e antecedência do aviso de auditoria (aspecto 6), nos trabalhos de Lélis e Pinheiro, e no de Kogeliski, Teixeira e Fagundes foram obtidos resultados variáveis, este fato se dá em função de setores diferentes serem entrevistados, sendo que seu dia a dia dentro da organização é dado de maneira diferenciada conforme os setores e assim consequentemente nas suas atividades desenvolvidas, através disso se justifica a diversidade das respostas, já nesta presente pesquisa os dados coletados sobre este aspecto é de $86 \%$ positivo, entâo das organizaçôes estudadas foi a única com maior positividade.

Outro aspecto questionado foi o clima durante a auditoria (aspecto 7), este fator é fundamental entre auditores e auditados para que ambos possam desenvolver suas atividades no processo de auditoria. Um dos artigos que se obteve divergência nas respostas foi o de Kogeliski, Teixeira e Fagundes, onde 18\% responderam que se tem um clima positivo, $53 \%$ atenção e $29 \%$ negativo. No artigo de Lélis e Pinheiro se tem com clima positivo $90 \%$, nesta presente pesquisa o indíce de maior percentual foi de atenção com $64 \%$ depois as respostas com $29 \%$ para positivo. Portanto percebe-se que este aspecto nestas organizaçóes pode ser trabalhado de maneira diferente, onde podem trabalhar para mudar os dados deste pois na maioria das vezes se tem um pensamento negativo sobre este aspecto e isso já é uma cultura que está nos colaboradores que pensar de tal forma como refletiram estas respostas.

Quanto ao empenho da área auditada em implementar os planos de ação (aspecto 8), um fator que chama atenção é que nesta presente pesquisa e na pesquisa de Kogeliski, Teixeira e Fagundes não possuim respostas negativas, isto significa que as respostas estão distribuídas em sua maioria positiva, e um indíce de atenção.

Referentes as melhorias dos controles internos (aspecto 9) nos dois artigos que são base para está pesquisa, as respostas sobre este aspecto entre ambos existe uma grande semelhança, no indíce positivo, atenção e negativo. Em relação a pesquisa atual a concentração das respostas estáo na opção positiva com $72 \%$ e o restante está dividido entre atenção e negativo.

Contabilidad y Negocios (12) 23, 2017 / ISSN 1992-1896 
Sobre o (aspecto 10) melhoria da gestão de riscos este é um fator importante para a organização pelo fato de prevenir futuros cenários negativos para a mesma, ou seja, a organização através de seus colaboradores deve exigir garantias dos associados que dela usufruem de produtos e serviços. Desta maneira é constatado nos artigos em estudo que existe uma melhoria na gestão destes riscos, pois responderam de forma positiva a grande maioria, sendo que nesta presente pesquisa não se obteve nenhuma resposta negativa. A avaliaçáo das atividades de riscos garantem a eficácia e eficiência dos controles e processos auditados, alinhados com o planejamento estratégico e auxiliando nas tomadas de decisōes. O objetivo é agregar valor às auditorias, pois centrada nos riscos acrescenta valor à organização, detectando fraudes ou erros onde pode haver impacto financeiro, atuando preventivamente nos riscos e garantido a clareza em relatórios utilizados na gestão para tomada de decisóes e servindo de apoio à gestão da Cooperativa.

$\mathrm{Na}$ melhoria do desempenho dos processos (aspecto 11), também não se obteve respostas negativas, nem mesmo no trabalho de Kogeliski, Teixeira e Fagundes, já 74\% foi positivo, e no artigo de Lélis e Pinheiro $75 \%$ positivo e $10 \%$ negativo sendo que este foi o único com indíce negativo e no atual trabalho $86 \%$ positivo, estás divirgências podem ser em função de que algum processo em determinado setor não é desempenhado como poderia ser, como também podem existir diversos fatores que possam interferir nos resultados.

Em relação ao monitoramento pela auditoria da execuçáo dos planos de açáo pelo auditado (aspecto 12) no artigo de Lélis e Pinheiro 81\% respondeu positivo, $16 \%$ atenção e $3 \%$ negativo, já no artigo de Kogeliski, Teixeira e Fagundes 38\% dos auditados responderam positivo, o maior indíce foi 53\% atenção, $9 \%$ negativo por fim no presente artigo foram destacados $21 \%$ atenção e $79 \%$ positivo, neste aspecto em ambas as organizacóes poderiam ter um enfoque especial para que este fator pudesse ser melhorado, pois poderia proporcionar uma visão diferente dos auditados nos planos de ação quanto as suas execuçôes, este fator pode gerar uma maior rentabilidade para as organizações em estudo.

Quanto á preparação do auditor para suas auditorias(aspecto 13), com relação á este aspecto cabe aos auditores terem conhecimento sobre as leis, normas que são estabelecidades e que regem a cooperativa, portanto, é de fundamental importância este individuo ter está preparação para suas auditorias, precisa ser qualificado para realizar seu trabalho com ética e eficiência. Através dos dados coletados percebe-se que a organização em estudo deve melhorar a preparação de seus auditores, isto segundo as respostas dos auditados que foram somente $64 \%$ positivo, bem como também se sugere qualificar osauditores da organização de estudo de Kogeliski, Teixeira e Fagundes com $59 \%$ positivo, enquanto no artigo de Lélis e Pinheiro $88 \%$ respondeu de forma positiva, isso significa que eles devem ter uma preparação melhor comparando com as outras organizações estudadas, a qual também pode aperfeiçoar seus trabalhos.

Sobre a qualidade das recomendaçóes de auditoria (aspecto 14), são através destas recomendaçóes que os auditados devem entender e melhorar o desempenho das tarefas que lhes são designadas conforme o que condiz em seus trabalhos, sendo assim, no trabalho de Lélis e Pinheiro 76\% positivo, no trabalho de Kogeliski, Teixeira e Fagundes já diminuiu um pouco para $62 \%$ positivo e por fim na presente pesquisa $79 \%$ positivos e ainda sobre esta, nenhuma das respostas foram negativas. 
Nas recomedaçóes de auditoria e melhor alinhamento do processo à estratégia corporativa (aspecto 15), através do resultado dos auditados este aspecto tem melhor desempenho na organização em que está sendo estudada no momento onde apenas $7 \%$ respondeu atenção, ou seja, somente uma pessoa e os outros $93 \%$ responderam positivo. Nos outros trabalhos comparando as respostas estão distribuídas entre as três alternativas, sendo sua maioria a alternativa positiva.

Quanto a relevância dos resultados reportados (aspecto 16) a organização estudada por Lélis e Pinheiro fica em destaque onde $94 \%$ dos auditados responderam de forma positiva, nos demais trabalhos comparados as respostas estão divididas em atenção e positiva, sendo ainda sua maioria.

A tempestividade da comunicação informal (aspecto 17), para os auditados na instituição financeira Crehnor obtiveram divisão de $50 \%$ para positivo e atenção, no artigo de Lélis e Pinheiro os resultados são 45\% atenção e $42 \%$ positivo e para Kogeliski, Teixeira e Fagundes $50 \%$ dos respostas são de atenção e 44\% positivo, desta maneira pode-se analisar que em ambas as organizaçóes devem rever este aspecto no dia a dia no desempenho de suas atividades, pois neste aspecto pode estar um grande diferencial a ser ajustado, no caso a comunição. Constatou-se também, a necessidade de uma melhoria no campo de formalização e comunicação. No que se refere a formalização, a inserçâo de um código de conduta ou regimento interno contribuiria. Tal extração é reforçada na análise do componente Informação e Comunicação.

E por último o aspecto questionado foi a tempestividade do relatório de auditoria (aspecto 18), para os auditados indiferente de seus setores no artigo de Lélis e Pinheiro 6\% negativo, $18 \%$ atençáo, $76 \%$ positivo já no artigo de Kogeliski, Teixeira e Fagundes os auditados responderam $65 \%$ atenção, $35 \%$ positivo e por fim as respostas dos auditados para a realização do presente artigo foram as seguintes apenas $7 \%$ negativo, $29 \%$ atenção e $64 \%$ positivo, sendo que o relatório de auditoria é um fator de grande importância para as organizaçôes de maneira geral, pois é através deste que são identificados os apontamentos nas auditorias e com isso está relacionado o tempo para tal atividade.

Portanto conclui-se através de todos os dados coletados que ambas as empresas estudadas cada uma possui regras, leis, políticas internas que norteiam as atividades da organização. E a partir deste conjunto de informçôes foi estudado as diferentes percepção dos auditados sobre as práticas de auditoria interna nos trbalhos mencionados anteriormente.

\section{Conclusóes}

Modernamente a auditoria interna, volta sua atenção para atuação preventiva e orientadora, desse modo esta passa a evitar as falhas involuntárias como também previne ou reduz fraudes, desperdícios ou abusos, ou seja, trata-se de benefícios advindos de um sistema de controle interno para o comprometimento de regras e normas estabelecidas pela própria cooperativa e também pelas fiscalizaçóes e regulamentaçóes seguidas pelo Banco Central do Brasil que é realizada temporariamente nas instituiçóes.

Através das aplicações de entrevistas, bem como de suas análises e comparaçóes entre os diversos aspectos abordados, desta maneira foi concluída esta pesquisa. Assim o objetivo foi atingido, sendo que se obtiveram diferentes percepçóes de acordo com cada item estudado e analisado, vindo a servir de apoio para o planejamento de gestão da organização.

Portanto considerando este cenário, a auditoria interna passa a tornar-se uma ferramenta confiável e estraté- 
gica, ao transmitir uma maior segurança a todos àqueles que utilizam de seus produtos e serviços, no que se refere á cooperativa e para seus associados e clientes.

No que se trata em responder o problema de pesquisa: qual é a percepção dos auditados sobre as práticas da auditoria interna em uma cooperativa de crédito? Desenvolveu-se um quadro comparativo a seguir que apresenta a resposta com maior número de escolhas em ambas as áreas analisadas neste estudo. Para cada aspecto questionado conforme o quadro 3, os auditados possuíam três alternativas de resposta, negativa (não, raramente), atenção (algumas vezes) e positiva (sim, muitíssimo).
Conforme o acima, no que se refere ao (aspecto 1), a grande maioria, ou seja, 78\% dos auditados perceberam positivamente a esta percepção. Já no (aspecto 2), na análise geral o estudo foi positivo para $93 \%$ dos auditados, eles acreditam que a adequação da condução dos trabalhos é de grande importância para a organização.No que se refere ao (aspecto 3), perceberam de forma positiva sob as análises das causas das deficiências 92\% dos auditados. No (aspecto 4) obteve-se um resultado positivo na analise geral, em que $85 \%$ dos auditados responderam, entre eles a maioria dos negócios com 36\%colaboradores, já no setor Administrativo e no de Habitação ambos com 14\%

Quadro 3. Comparativo das respostas estratificadas.

\begin{tabular}{|c|c|c|c|c|c|c|c|c|c|}
\hline & Aspectos & & $\begin{array}{l}\operatorname{minis} \\
\text { ativa }\end{array}$ & & ixa & Neg & ócios & Habit & ação \\
\hline 1 & Aceitação pelo auditado das deficiências encontradas pelo auditor. & $\mathrm{P}$ & $7 \%$ & $\mathrm{P}$ & $21 \%$ & $\mathrm{P}$ & $36 \%$ & $\mathrm{P}$ & $14 \%$ \\
\hline 2 & Adequação da condução dos trabalhos pelo auditor. & $\mathrm{P}$ & $14 \%$ & $\mathrm{P}$ & $29 \%$ & $\mathrm{P}$ & $29 \%$ & $\mathrm{P}$ & $21 \%$ \\
\hline 3 & Análise das causas das deficiências pelo auditado & $\mathrm{P}$ & $14 \%$ & $\mathrm{P}$ & $21 \%$ & $\mathrm{P}$ & $36 \%$ & A & $21 \%$ \\
\hline 4 & Auditoria como fonte consultiva. & $\mathrm{P}$ & $14 \%$ & $\mathrm{P}$ & $21 \%$ & $\mathrm{P}$ & $36 \%$ & $\mathrm{P}$ & $14 \%$ \\
\hline 5 & Avaliação geral da eficácia do processo de auditoria intema. & $\mathrm{P}$ & $14 \%$ & $\mathrm{P}$ & $29 \%$ & $\mathrm{P}$ & $36 \%$ & $\mathrm{~N} / \mathrm{A} / \mathrm{P}$ & $7 \%$ \\
\hline 6 & Formalização e antecedência do aviso de auditoria. & $\mathrm{P}$ & $14 \%$ & $\mathrm{P}$ & $29 \%$ & $\mathrm{~A} / \mathrm{P}$ & $14 \%$ & $\mathrm{P}$ & $21 \%$ \\
\hline 7 & Clima durante a auditoria & A & $7 \%$ & A & $21 \%$ & $\mathrm{~A} / \mathrm{P}$ & $14 \%$ & A & $14 \%$ \\
\hline 8 & Empenho da área auditada em (tjtptefOHJÍac os planos de ação. & $\mathrm{P}$ & $14 \%$ & $\mathrm{P}$ & $21 \%$ & $\mathrm{P}$ & $29 \%$ & $\mathrm{P}$ & $21 \%$ \\
\hline 9 & Melhona dos controles internos. & $\mathrm{P}$ & $14 \%$ & $\mathrm{P}$ & $14 \%$ & $\mathrm{P}$ & $29 \%$ & $\mathrm{P}$ & $14 \%$ \\
\hline 10 & Melhona da qestão de riscos & $\mathrm{P}$ & $14 \%$ & $\mathrm{P}$ & $21 \%$ & A & $21 \%$ & $\mathrm{P}$ & $14 \%$ \\
\hline 11 & Melhoria do desempenho dos processos. & $\mathrm{P}$ & $14 \%$ & $\mathrm{P}$ & $29 \%$ & $\mathrm{P}$ & $21 \%$ & $\mathrm{P}$ & $14 \%$ \\
\hline 12 & Monitoramento pela auditoria da execução dos planos de ação pelo auditado & $\mathrm{P}$ & $14 \%$ & $\mathrm{P}$ & $21 \%$ & A & $29 \%$ & $\mathrm{P}$ & $14 \%$ \\
\hline 13 & Preparação do auditor. & A & $7 \%$ & $\mathrm{P}$ & $21 \%$ & $\mathrm{P}$ & $21 \%$ & $\mathrm{P}$ & $14 \%$ \\
\hline 14 & Qualidade das recomendaçóes de auditoria. & A & $7 \%$ & $\mathrm{P}$ & $29 \%$ & $\mathrm{P}$ & $29 \%$ & $\mathrm{P}$ & $14 \%$ \\
\hline 15 & $\begin{array}{l}\text { Recomendaçóes de auditoria e melhor alinhamento do processo à estratégia } \\
\text { corporativa. }\end{array}$ & A & $7 \%$ & $\mathrm{P}$ & $29 \%$ & $\mathrm{P}$ & $36 \%$ & $\mathrm{P}$ & $21 \%$ \\
\hline 16 & Relevância dos resultados reportados & $\mathrm{P}$ & $14 \%$ & $\mathrm{P}$ & $21 \%$ & $\mathrm{P}$ & $29 \%$ & A & $14 \%$ \\
\hline 17 & Tempestividade da comunicação informal. & A & $14 \%$ & $\mathrm{~A} / \mathrm{P}$ & $14 \%$ & $\mathrm{P}$ & $21 \%$ & $\mathrm{P}$ & $14 \%$ \\
\hline 18 & Tempestividade do relatório de auditona & A & $14 \%$ & $\mathrm{~A} / \mathrm{P}$ & $14 \%$ & $\mathrm{P}$ & $29 \%$ & $\mathrm{P}$ & $14 \%$ \\
\hline
\end{tabular}

Fonte: Dados da pesquisa. 
dos entrevistados. No que tange o (aspecto 5) as percepçóes em uma análise verificou-se que nos setores administrativo, caixa e negócios de forma positiva, já no setor da habitação este aspecto ficou dividido entre as três opções de respostas.

Em relação ao (aspecto 6), que se refere a formalização e antecedência do aviso da auditoria entre os auditados do setor de negócios estes perceberam com atenção e com positividade, já os demais setores avaliaram de forma positiva este aspecto. Referente à análise geral do (aspecto 7), sobre o clima durante a auditoria obtivemos atenção como resultado para os setores administrativo, caixa, habitação, somente o setor de negócio que obteve resultados de positividade e atenção. No (aspecto 8) as percepçóes na análise geral foram positivas para todos os setores, portanto entende-se que os auditados realmente sentem a necessidade de plano de ação isto faz com que emprenho também contribua a o desenvolvimento das atividades organizacionais. Em análise realizada sob o (aspecto 9) melhoria dos controles internos, obtivemos através do resultado geral que o mesmo foi positivo. De modo que para a organização este aspecto traz inúmeros benefícios facilitando o dia a dia do auditado em seu trabalho.

Em relação ao (aspecto 10), na análise geral os auditados perceberam positivamente o aspecto, diferente da área de negócios que percebeu com atenção. Já o (aspecto 11), também se obteve percepçóes positivas na análise geral mantendo-se essa percepção em todas as áreas. Referente ao (aspecto 12) que também foi positiva em $78 \%$ dos setores entrevistados, já no setor de negócios avaliou e obteve com atenção revelando o monitoramento pela auditoria da execução dos planos de ação pelo auditado náo suficientes que este pode ser melhor conduzido. O (aspecto 13) foi percebido positivamente enquanto $56 \%$ dos entrevistados mantiveram-se positivos no aspecto e somente o administrativo manteve-se com atenção. Este aspecto revela que a preparação do auditor neste aspecto é de que os auditores podem ser melhores preparados em relaçáo aos procedimentos de funcionamento de leis e regras nestas unidades de atendimento.

Quanto ao (aspecto 14) a percepção foi de atenção no setor administrativo, sendo diferente a percepçáo da área de negócios, caixa e habitação estes que tiveram percepção positiva neste aspecto. No que tange o (aspecto 15) a percepção foi de atenção para o setor administrativo, onde para eles este aspecto estudado deve-se ter melhoria nas recomendaçóes de auditoria e melhor alinhamento do processo à estratégia corporativa, os demais setores entenderam positivamente o estudo. A percepçáo no (aspecto 16), onde $64 \%$ dos entrevistados na análise geral, responderam positivamente, menos a área administrativa que percebeu este aspecto com atenção. No (aspecto 17) a percepção foi positiva com para os setores de negócio e habitação, diferente da área administrativa que percebeu com atençáo e ainda o setor do caixa que perceberam com atençáo e positivamente. E por fim a analise realizada no (aspecto 18) a percepção foi de atenção para o setor administrativo, para o setor dos negócios e habitação revelou-se positivo e para o setor do caixa que percebeu com atenção e positivamente a tempestividade do relatório de auditoria após o desenvolvimento deste, eles entendem que o processo deve ser mais acelerado quando trata de devolução para a instituição que está sendo analisada, seria uma crítica construtiva.

Assim o objetivo de identificar a percepção dos auditados sobre as práticas de auditoria interna, foi atingido, pois foi possível identificar as diferentes percepçóes de cada auditado, e também ficou claro que conforme cada setor da organização os colaboradores tem uma 
percepção diferente, isto ocorre em função de cada um destes desenvolve tarefas diferentes, mas que indiferente de sua função seguem as regras e processos vigentes na instituição.

Com relação à auditoria interna baseada em riscos, pode-se concluir que, para sua implantação é necessário identificar e avaliar os riscos existentes, com o auxilio de reuniões com os gestores, auditores é possível prevenir erros e fraudes. Com maior expressividade de opinióes as sugestóes de melhorias para o processo de auditoria referem-se ao monitoramento do relatório de auditoria de forma permanente pela equipe de auditores de forma a cobrar a solução dos problemas nos prazos propostos; necessidade de melhoria na linguagem utilizada nos relatórios para facilitar o entendimento do gestor; destinar maior tempo para os trabalhos nas singulares visando contribuir na gestão e retirando dúvidas do quadro diretivo e colaboradores, além de outras sugestôes com menor representatividade de opinião.

Com relação ao artigo realizado dos dados coletados primeiramente foram analisados os itens sobre as características pessoais dos colaborados e a partir disso foi possível analisar os aspectos da auditoria interna. Este objetivo também foi atingido, pois vários níveis de auditoria foram mencionados e pode-se concluir que os fatores analisados refletem diretamente na organização, assim os indicadores de auditoria interna poderão contribuir na melhoria da gestão organizacional.

Portanto, para aprofundar e ampliar a base de conhecimento sobre a auditoria interna sugere-se a realização de estudos futuros que estejam relacionados às características observadas na auditoria interna, porém está pesquisa servirá de base para continuação e posteriores estudos, tanto na cooperativa, comunidade acadêmica e demais profissionais.

\section{Referências}

Ancosol (2016). Os sistemas cooperativos e os ramos do cooperativismo. Disponível em: http://www.ancosol. org.br/ramos_cooperativismo.php. Acesso em 27 de março de 2016.

Borely, A. M., Cardoso, J. S. de S. (2005). Auditoria como ferramenta estratégica de controles de ONGS. Revista de Contabilidade do Mestrado em Ciências Contábeis da UERJ, 1, p.44. Jan/abr. Rio de Janeiro.

Crehnor (2016) Cooperativismo, Objetivos, Princípios. $<$ Disponível em:www.crehnor.com.br>. Acesso em 27 de Março de 2016.

Fajardo, J. de M, Wanderley, C. A. N. (2010). Planejamento Estratégico e Auditoria de Gestão: similaridades com o modelo COSO. Revista Contexto, 17, Jan/Jun, 93-103. Porto Alegre.

Franco, H. (2001). Auditoria Contábil. 4. ed. São Paulo: Atlas.

Gil, A. C. (2002). Como elaborar projetos de pesquisa. 4 ed. São Paulo: Atlas.

Kogeliski, B., Teixeira, D. J., Fagundes, J. A. (2014). Percepção dos Auditados Sobre as Práticas de Auditoria Interna. Apresentado no VIII Congresso Iberoamericano de Contabilidad de Gestión e o X Congresso Iberoamericano de Administración Empresarial y Contabilidad na cidade de Medellín-Colômbia.

Kowalski, F. D., Fernandes, F. C., de Faria, A. C. (2010). Análise dos Controles internos Relacionados às Atividades Ambientais das Cooperativas de Energia Elétrica por meio da Matriz de Importância-Desempenho de Slack. Revista Contabilidade Vista \& Revista, 2, 153-177. Minas Gerais, Belo Horizonte, Abr./jun.

Lago, A., Silva, T. N. da. (2011). Fatores Condicionantes do Desenvolvimento de Relacionamentos Intercooperativos no Cooperativismo Agropecuário. Porto Alegre: SESCOOP/RS. 
Lélis, D., Pinheiro, L. (2012). Percepção de Auditores e Auditados sobre as Práticas de Auditoria Interna em uma Empresa do Setor Energético. Revista Contabilidade e Finanças, 60Set/dez, 212-222. São Paulo. https://doi. org/10.1590/S1519-70772012000300006

Macedo, B., Ximenes, J. A. (2003). Cooperativismo: doutrina, descompassos e prática. Goiânia: Unimed.

Marconi, M. A., Lakatos, E. M. (2008). Técnicas de pesquisa: planejamento e execução de pesquisa, amostragens e técnicas de pesquisa, elaboração, análise e interpretação de dados - SP: Atlas.

Mello, A. O. (2002). O que é auditoria interna? Disponível em: http://www.auditoriainterna.com.br/conceitos. htm\# oquee. Acesso em: 28 de março de 2016.

Oliveira, D. S., Gomes, G. F. da F., Porto, L. C de M.(2012). A Importância da Auditoria Interna no processo de Gestâo das Organizaçóes em um ambiente globalizado e cada vez mais competitivo. Revista de Ciências Gerenciais, 1 (1), 2-19

Santos, M. I. (2008). A influência da aplicação dos mecanismos e instrumentos de auditoria nos resultados da cooperativa de crédito de uma instituiçấo federal de ensino tecnológico-CEFET-PB. Revista UnB Contábil, 1-2, Jan/dez, 104-116. Brasília.

Schardong, A. (2003). Cooperativa de Crédito: Instrumento de Organização Econômica da Sociedade. 2. ed. Porto Alegre: Rigel.

Silva, A. S., Inácio, H. C. (2013). A relação entre a auditoria interna e a auditoria externa e o impacto nos honorários dos auditores externos. Revista Universo Contábil, 1. Jan/mar, 135-146. Blumenau. https:// doi.org/10.4270/ruc.2013108
Silva, P. G. K. da. (2002). O papel do controle interno na administração pública. Revista Contexto, 2. Jan/jun. Porto Alegre.

Soares, M. de A. (2007). Auditoria interna aplicada em uma instituição filantrópica hospitalar. Revista Contexto, 11. Jan/jun, 1-26. Porto Alegre.

Suzart, J. A. da S. (2012). Ser ou não ser independente? Um estudo exploratório sobre a independência das instituiçôes superiores de auditoria e o nível de transparência fiscal dos países. Revista Universo Contábil, 3, Jul/Set, 24-39. Blumenau. https://doi.org/10.4270/ ruc. 2012320

Vergara, S. C. (2009). Projetos e relatórios de pesquisa em administraçâo. São Paulo: Atlas.

Wisnievski, G. (2004). Manual de contabilidade das sociedades cooperativas. Belo Horizonte: Mandamentos.

Fecha de recepción: 22 de setiembre de 2016 Fecha de aceptación: 28 de marzo de 2017 cintia.bussler@gmail.com jair_fagundes@hotmail.com edio.pk@gmail.com clebia.ciupak@gmail.com afbsantana@hotmail.com 